\title{
Reconstruction of the terrazzo surface in the exterior
}

\author{
Michal Novotný ${ }^{1, *}$, and Barbora Nečasová ${ }^{1}$ \\ ${ }^{1}$ Vysoké učení technické v Brně, Fakulta stavební, Ústav Technologie, mechanizace a řízení staveb, \\ Veveř́ 331/95, Brno, Czech Republic
}

\begin{abstract}
The article deals with terrazzo surface that is done in the exterior and which shows defects and faults after execution. It was an entry portal of an unnamed institution where the placed surface began to show flaws more or less immediately after laying. The article simply provides a research of the problem, deals with the proposed procedure and presents the results of the technology supervision. Currently, after the second execution, the surface again shows defects and the way of their remedy will be addressed. The article also presents the basic aspects that need to be respected and not neglected when this type of surface is realized. Terrazzo is primarily an interior material (in our conditions), but it is also possible to make it in the exterior - it is a special kind of concrete mixture. The article tries to summarize the issue and provide basic information about the problem and its solutions.
\end{abstract}

\section{What is terrazzo?}

What exactly is terrazzo? Its name comes from Italian. In the Czech Republic, however, it is more frequently called "teraco" or "teraso". But what can one picture under that name? In general, this material can be compared to artificial stone. It is a concrete mixture with admixtures of various aggregates, especially natural stone (e.g. limestone, as required) with the possibility of addition of pigments. It is normally applied to a bearing base structure, mostly concrete, in thicknesses of $1.5-3 \mathrm{~cm}$. These thicknesses apply to the interior, however, it is necessary to allow for thermal changes of the structure in the exterior and thus adapt both the expansion units and the thickness of the applied layer to this fact. Most commonly, a mixture prepared like this imitates the natural stone structure - the mixture, due to this composition, takes over not only positive properties such as strength or surface resistance, but also some imperfections. For example, the unevenness of the aggregate grain distribution or added colour can be mentioned (this can be addressed by proper mixing and application, but cannot be ruled out). Another imperfection is the content of small pores and hairline cracks on the surface. While these are accepted in second-rate surfaces, such imperfections must be sealed with cement milk in case of the final surfaces in places with the importance of appearance, and then the surface is treated again. Terrazzo surface as such is treated by grinding, bush hammering, blasting, brushing and other techniques, according to the appearance to be achieved. Grinding on

\footnotetext{
*Corresponding author: novotny.m1@,fce.vutbr.cz; novotny.m1@,seznam.cz
} 
cast surfaces is carried out directly on site, while prefabricated parts can be ground directly in the production where it is more accurate. Terrazzo surface itself may not only be a mixture of aggregates, but may be combined with both stone and ceramic components, as well as, for example, metal elements. Otherwise untreated surface is rather matte after grinding and washing, but it can be treated to be gloss by chemical means. For enhanced durability, it is also provided with paint sealants such as wax, varnish, dispersions, or formerly with linseed oil. It is most commonly used in public space with a large activity of people where decorative appearance is required for low financial investment - for example halls, shopping arcades, building entrances, landings and half-landings, stairs. It can also be used as a wear layer in kitchens, corridors, hallways and sanitary facilities in houses or flats. It can be applied to walls as well.

The base for terrazzo surfaces must always be a concrete layer made of concrete of at least class $\mathrm{C} 25 / 30$ or according to the design of the structure (influence of deflection and creep cracking). The best-quality floors of this type are made by the "fresh to fresh" system. This means that the bearing floor layer is processed when the base is still fresh, i.e. within two hours at the latest. However, this is not normally possible at construction sites. Therefore, when terrazzo base concrete is older, terrazzo can be used directly on a coarse but levelled adhesive-bonded base. Such base must be treated before application of the adhesive bridge by bush hammering and must be moistened for at least 12 hours. Part of the design, especially in the exterior, is the execution of expansion joints for movements due to thermal stress. Cutting of the joints must be done no later than 12 hours after making, and the cut in the terrazzo layer must be the same or wider than the width of the joint in the bottom base concrete. Field sizes must also be determined with regard to structural stress. Failure to do so may cause a so-called pillow effect, which means that if the temperature increases, it may lead to crushing of the terrazzo joint part or cracking of the surfaces.

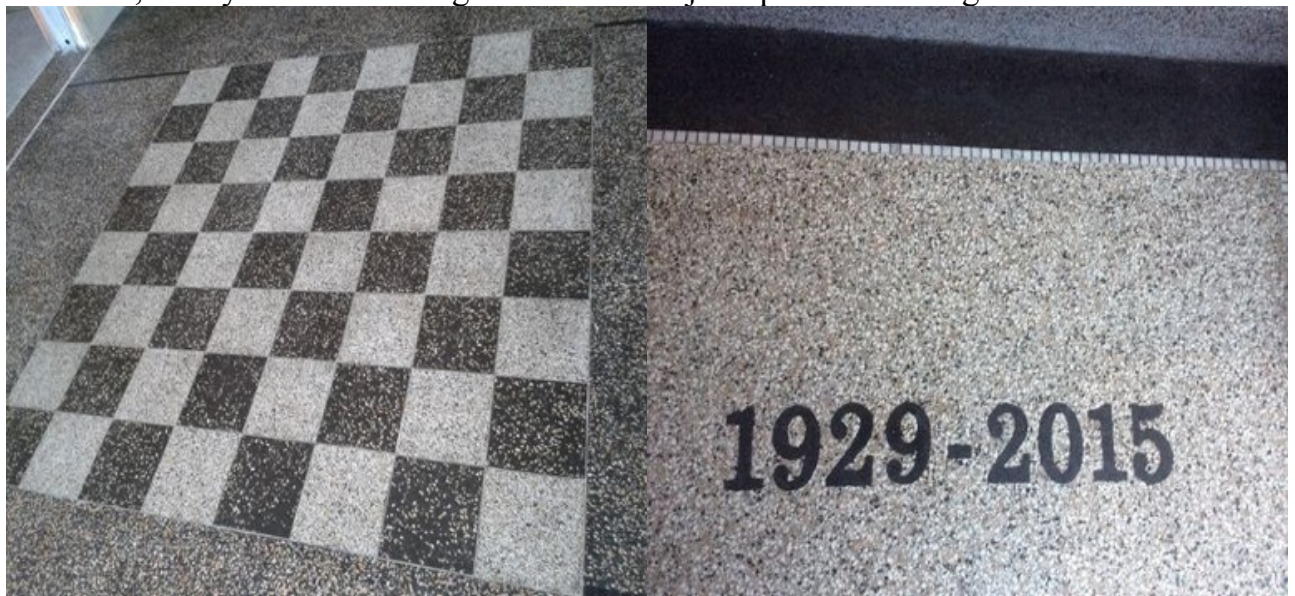

Fig. 1. Various terrazzo designs - even with the embedded decorative inscription

Terrazzo, like other finishes and finishes, must be made at a certain level of quality. As a final surface they are then him high demands not only technologically, but also from other perspectives - eg. durability, abrasion resistance, flatness, design according to project documentation, the exterior also slip, surface gradient (drain rainfall), the size of "expansion" fields of temperature changes and more. Most of these requirements are dealt with by Czech State Standards (Technical standards for Czech republic) in connection with the basic building legislation. These are, for example, basic geometric accuracy, inclinations and surface finish of "floors", parameters of materials and components used. Only in compliance with all these parameters, project documentation and technological procedures can we design a construction according to the requirements of the investor with high utility values. $[1,2,3,4,5,6]$ 


\section{Opinion of terrazzo condition at the entrance portal of a public institution}

I was invited to be a technology supervisor of terrazzo implementation for the event "Reconstruction of the Entrance Portal" (neither the institution nor the city can be named investor's request). This was in response to emerged cracks on the newly made terrazzo surface which was the wear layer of this structure. Cracks originated essentially immediately after the surface was finished and ground. At the initial stage, an in-situ inspection was required to identify possible causes of the cracking. Consequently, it was required to perform a technology supervision to remedy the condition, if it was agreed at the meeting regarding the condition that the solution will be done by removing the terrazzo and implementing a new one. This happened eventually, and a new version of the terrazzo layer was required as the fastest solution due to the completion date of the construction.

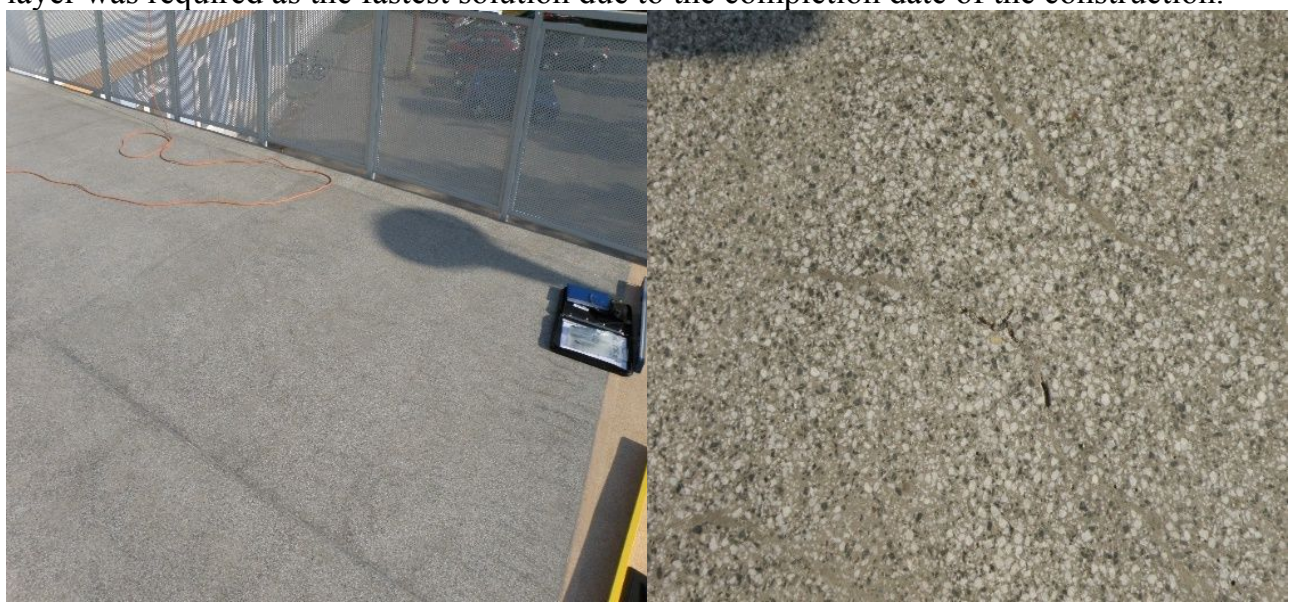

Fig. 2. Photo of the damaged original terrazzo layer

Based on the survey of 12 September 2016, when we were at the site with an expert, Mr. Ing. Zdeněk Nevosád, cracks in the surface were found, and it was discovered by tapping that a large part (80\%) of the surface was separated from the base. The shape of the cracks indicated an imperfect implementation or large deflections of the base, while pillow effect was not primarily found. Closure of the cracks was not possible, they were larger than hairline ones and the layer had already separated from the base. Another cause could be seen in large expansion units on the surface -4 fields of approximately $2 * 2 \mathrm{~m}$, which, due to the possibilities of deflections of the base, was too much. The identified defects can be described as follows:

- cracks caused by improper execution technology, hardening treatment,

- non-penetrated base without adhesive bridge,

- large expansion fields.

The investor agreed that the terrazzo layer would be removed and newly implemented to the detriment of the contractor, which was obvious due to the poor execution. I was involved in this as a technology supervisor, and my task was to ensure the correct laying and observance of the technology in terms of application and treatment. Subsequently, after a consultation with a structural engineer who assessed the structure, a smaller dilatation field of about $1.5^{*} 0.9 \mathrm{~m}$ was proposed. It was recommended to use even $0.9 * 0.9 \mathrm{~m}$, but the investor did not want to accept this. Another recommendation followed by the contractor was the execution of a contact bridge to guarantee the connection of dry concrete and the terrazzo layer. Due to the speed of work progress and non-communication on the part of the 
contractor, there was another discrepancy during the new implementation, namely the unification concrete layer, which reduced the thickness of the terrazzo layer. This subsequently had an impact on a new damage in May of the following year, when also imperfections of the surfaces on the stairs, which had appeared to be all right, became evident. The steps recommended to the contractor and the investor for the new layer execution leading to the correct repair were as follows:

A) In terms of designing:

- Follow possible deflections set by the structural engineer - approx. $10 \mathrm{~mm}$ according to available information, [6]

- Adjust the size of contraction/expansion units - recommended approx. 0.9 x 0.9 m. [3,4]

B) In terms of implementation technology:

- Perfectly clean the base from mechanical impurities, the rest of the previous layers, do not allow chemical penetration of the base.

- Start moistening the base with water at least 6 hours before concreting. Second moistening done about 4 hours and another one about 2 hours before concreting. About 30 minutes before concreting, remove excess water from the surface - surfacemoistened with water mist. [4]

- Choose a suitable time for concreting with regard to the ambient temperature, limit concreting under high heat - average temperature at the time of execution $25{ }^{\circ} \mathrm{C}$, concrete in checked patter. [4]

- After concreting, cover the surface with previously well moistened geotextile, which must be suitably anchored against wind blowing, maintain its moisture. [4]

- The remaining field of the checkerboard pattern may be concreted not earlier than 48 hours after the first concreting.

- Prior to the grinding of the surface, the geotextile is pushed away, grinding is performed and the whole surface is refilled (cavity filling). Continue with the moistening until the age of the youngest concrete of about 7 days depending on the weather.

- The final grinding and surface cleaning (slopes, water outflow) will be carried out and a water test will be conducted to remove water from the surface, and any areas with puddles will be eventually grinded again, and a final rehabilitation of any exposed minor defects and cracks is done.

- Before winter, but at least 28 days in the concrete age, impregnation (penetration) is applied to increase the resistance of the concrete surface to the freezing and salt. The most effective products are boiled linseed oil based products.

These were the basic monitored steps that the company carried out in a quality that complies with the regulations. They used their own initiative only when concreting the unification layer (with specifications unknown to the supervisor), which reduced the thickness of the terrazzo layer to an average of $15 \mathrm{~mm}$, which was not directly inconsistent with the guidelines, but the practice and standards did not recommend a thickness of less than $20 \mathrm{~mm}$ for these layers. This step proved, after one year of operation, to be another problem, when the unification layer worked more like an expansion layer.

After the repairs were completed, the work was subsequently taken over, but with reservations for the carried out grinding - during the work, the workers were repeatedly notified of the grinding process. In particular, it was about grinding "in the area" so that there would not be larger grinding of one spot, which could create a so-called "bowl", a low puddle-forming place. This was unfortunately done in two places, however, it was on the edges, where a small amount of standing water was not a problem. From the point of view of grinding and repairs of part of the structure (the edges of the area were not affected by the removal), the most problematic proved to be the creation of a slope for water outflow. The slopes were very small, even non-existent at the spot of connection to the existing threshold entry structure, which the 
supervisor considered to be a fault - but this was not in conflict with the standard, because the documentation did not indicate the value of the slopes, while it should have. This repaired layer was in operation for approximately one year before further damage occurred. The causes were more or less the same, moreover the impact of the unification layer and the reduced thickness of the surface had an effect. Damage also occurred on the surface of the stairway, which was sound during the original repairs, and the cause is probably due to the influence of leakage and surface treatment in the winter.

Further talks were convened to make repairs, again with our recommendation not to carry out terrazzo on this structure due to its maximum thickness of $20 \mathrm{~mm}$. As a result of the talks, the investor's decision was only to rehabilitate the surface in cooperation with a new firm for the time being - after the experience, the original one came to an agreement on another form of compensation with the investor. The result of the new company's proposal has not been passed on to us and the current state is unknown, the last known condition is the original one with damage before the summer holidays of 2017.

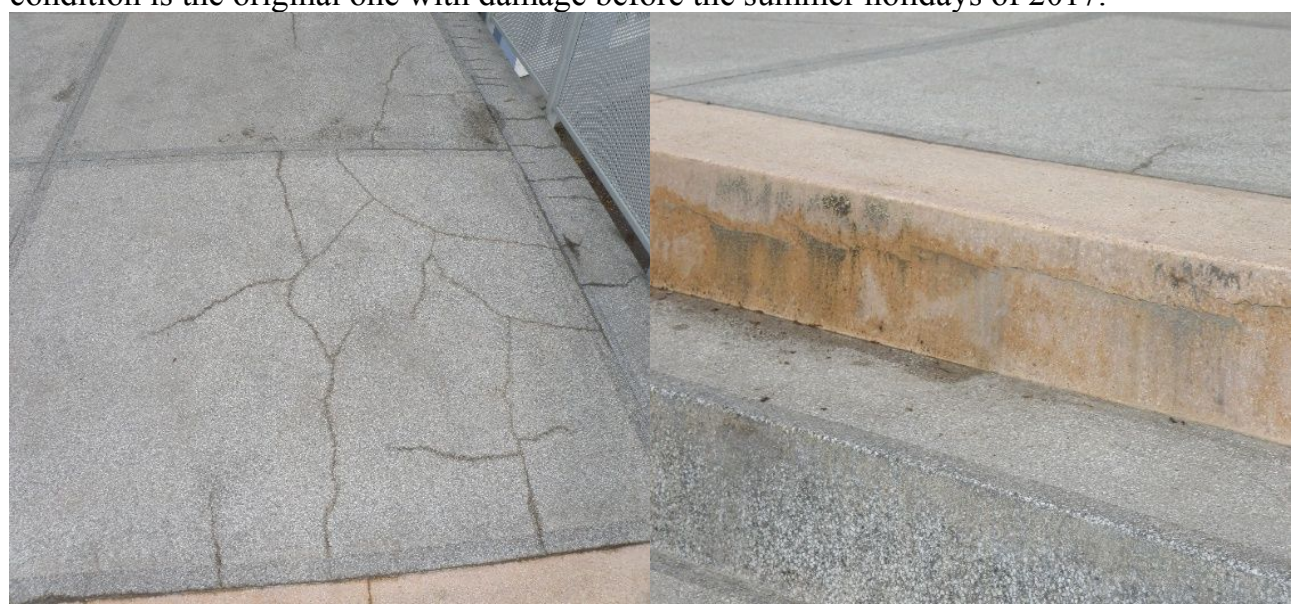

Fig. 3. Photo of surface and stairs damage during a new inspection in May 2017

The abovementioned structural defects cannot be judged in relation to other objects. The authors are not familiar with the experience of another terrazzo case of a similar design in the external environment. It is therefore not possible to refer to the above mentioned data in general on all external terraces. It will be the subject of a further procedure for securing data from similar implementations if they have occurred in order to compare the detected defects and procedures with other constructions.

Only on the basis of such an investigation will it be possible to say whether the general exterior terrazzo surfaces are very problematic, or whether the assessed implementation has been flawed for only a few reasons.

\section{Conclusion and Evaluation}

What to say in conclusion? Terrazzo is a very visually beautiful surface at lower cost of acquisition. Its benefits are most prominent in interiors. As far as the exterior is concerned, since the material is done as a cement mortar layer, it can be used. However, it is necessary to adjust the performance parameters and observe the basic rules for the application of external screeds (terrazzo is de facto "concrete screed" with special aggregate). The basic rules that we must be careful about are the execution of the overall drainage of the structure, perfect preparation and execution of the bearing base or structure, adherence to the technological rules of laying, which includes the execution of "expansion" units and adherence to the minimum thickness of the layer, which is recommended to be at least 40 
$\mathrm{mm}$ (influence on the price of terrazzo - the interior thickness is $20 \mathrm{~mm}$ ) and, last but not least, adherence to the process and the length of treatment of the layer. If all of these parameters are observed, done and everything is properly designed, it can be said that a very good result can be expected. Of course, regular maintenance and treatment of the surface is also a matter of course because we are talking about a heavily used surface and it is necessary to get rid of snow or ice in the winter, which is often done with chemical deicing or salting. Terrazzo surface must be protected against these substances. Around these parts, however, the use of terrazzo is not common, and it is difficult to find relevant information for performing such surfaces under such atypical conditions like during this event - the "bridge" type structure with larger deflections, outer environment, thin layer in the design, large expansion fields. When the complications in the form of inappropriate procedures and non-observance of treatment technology appear, a result that would be effective in appearance and with great durability and life cannot be achieved. It is therefore necessary to take all aspects into account at the design stage and to address them in synergy with the designer/contractor/investor.

\section{References}

1. ČSN EN 13318 Screed materials and floor screeds - definitions (Czech Standards Institute, Prague, July 2001)

2. ČSN EN 13813 Screed materials and floor screeds - screed materials - properties and requirements (Czech Standards Institute, Prague. November 2003)

3. ČSN 744505 Floors - common provisions. 28 pages (The Office for Standardization, Metrology and Testing, Prague, May 2012)

4. ČSN EN 13670 Implementation of concrete structures (The Office for Standardization, Metrology and Testing, Prague, June 2010)

5. ČSN EN 12620+A1 Aggregates for concrete (The Office for Standardization, Metrology and Testing, Prague, November 2008)

6. ČSN 73 0212-3 Geometrical accuracy in building industry. Accuracy checking. Part 3: Building structures (Czech Standards Institute, Prague, January 1997) 